\title{
Fruit and vegetable intakes in relation to plasma nutrient concentrations in women in Shanghai, China
}

\author{
Cara L Frankenfeld', Johanna W Lampe 2,3,4,*, Jackilen Shannon ${ }^{5}$, Dao L Gao ${ }^{6}$, \\ Wenjin $\mathrm{Li}^{2}$, Roberta M Ray ${ }^{2}$, Chu Chen ${ }^{2,3}$, Irena B King ${ }^{7}$ and David B Thomas ${ }^{2}$ \\ 'Department of Global and Community Health, George Mason University, Fairfax, VA, USA: ${ }^{2}$ Fred Hutchinson \\ Cancer Research Center, 1100 Fairview Avenue N, M4-B402, PO Box 19024, Seattle, WA 98109-1024, \\ USA: ${ }^{3}$ Department of Epidemiology, University of Washington, Seattle, WA, USA: ${ }^{4}$ Department of Nutritional \\ Sciences, University of Washington, Seattle, WA, USA: ${ }^{5}$ Department of Public Health and Preventive \\ Medicine, Oregon Health and Science University, Portland, OR, USA: ' Zhong Shan Hospital Cancer Center, \\ Shanghai, People's Republic of China: ${ }^{7}$ Department of Medicine, University of New Mexico, Albuquerque, \\ NM, USA
}

Submitted 23 August 2010: Accepted 5 April 2011: First published online 6 June 2011

\begin{abstract}
Objective: To evaluate the validity of fruit and vegetable intakes as it relates to plasma carotenoid and vitamin $\mathrm{C}$ concentrations in Chinese women, using three classification schemes.

Design: Intakes were calculated using an interviewer-administered FFQ. Fruits and vegetables, botanical groups and high-nutrient groups were evaluated. These three classification schemes were compared with plasma carotenoid and vitamin C concentrations from blood samples collected within 1 week of questionnaire completion. Setting: Shanghai, China.

Subjects: Participants ( $n$ 2031) comprised women who had participated in a casecontrol study of diet and breast-related diseases nested within a randomized trial of breast self-examination among textile workers ( $n$ 266 064)

Results: Fruit intake was significantly $(P<0.05)$ and positively associated with plasma concentrations of $\alpha$-tocopherol, $\beta$-cryptoxanthin, lycopene, $\alpha$-carotene, $\beta$-carotene, retinyl palmitate and vitamin $C$. Fruit intake was inversely associated with $\gamma$-tocopherol and lutein + zeaxanthin concentrations. Vegetable consumption was significantly and positively associated with $\gamma$-tocopherol and $\beta$-cryptoxanthin concentrations. Each botanical and high-nutrient group was also significantly associated with particular plasma nutrient concentrations. Fruit and vegetable intakes and most plasma nutrient concentrations were significantly associated with season of interview.

Conclusions: These results suggest that the manner in which fruits and vegetables are grouped leads to different plasma nutrient exposure information, which may be an important consideration when testing and generating hypotheses regarding disease risk in relation to diet. Interview season should be considered when evaluating the associations of reported intake and plasma nutrients with disease outcomes.
\end{abstract}

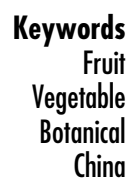

Higher consumption of fruit and vegetables has been associated with lower risk of several diseases, including heart disease and several cancers ${ }^{(1-4)}$. Fruits and vegetables contain numerous phytochemicals that may reduce disease risk. High fruit and vegetable intakes may also be a marker for an overall diet or for other lifestyle factors associated with reduced disease risk. Observations regarding disease risk in relation to broad and heterogeneous categories, such as 'fruits' and 'vegetables', have direct implications for public health recommendations, such as 'two cups of fruit and $2 \frac{1}{2}$ cups of vegetables per day are recommended for a reference 2000-energy intake' according to the US Department of Agriculture Dietary Guidelines for Americans 2005 ${ }^{(5)}$. Evaluation of fruits and vegetables classified on the basis of their nutrient content, such as on the basis of particular vitamins or other phytochemicals, is useful for generating hypotheses regarding the biological mechanisms of associations of fruit and vegetable intakes with disease risk.

Many studies on the association between fruit and vegetable intakes and disease risk have been conducted in Western populations; however, fewer data are available on other population groups. The amount and patterns of fruit and vegetable consumption may differ across 
populations. For example, fruit and vegetable intakes in South-East Asia are lower than those of Western populations $^{(6)}$. A difference in the amount or pattern of consumption may affect the validity and interpretation of dietary intake data.

Our primary objective was to evaluate the validity of fruit and vegetable intakes obtained from an FFQ by evaluating various classification schemes in relation to plasma carotenoid and vitamin $\mathrm{C}$ concentrations. Additional analyses were conducted to evaluate dietary intake and plasma concentrations in relation to season of interview and year of interview to evaluate potential bias that might be introduced by these variables.

\section{Experimental methods}

\section{Participants and study procedures}

Participants ( $n$ 2031) comprised women who had participated in a case-control study of diet and breast-related diseases nested within a randomized trial of breast selfexamination among textile workers in Shanghai, China ( $n$ 266064; Fig. 1) ${ }^{(7)}$. Figure 1 illustrates the selection of participants for the analysis conducted for the present study from the larger randomized trial. Recruitment into the trial took place between 1989 and 1991, and followup for breast-related diseases continued through July 2000. Women born between 1925 and 1958 were eligible for participation in the trial (aged 30-64 years at enrolment). Further details regarding eligibility for the randomized trial and baseline data collection are published elsewhere $^{(8)}$. Dietary data were collected from selected women in the cohort with benign or malignant breast disease diagnosed between 1 September 1995 and 31 July 2000 and from women without breast diseases who were randomly selected from the trial cohort as controls ${ }^{(9)}$. Controls were frequency-matched to cases on the basis of age. Women with breast-related diseases were eligible as cases for the case-control study if they were diagnosed at one of the three hospitals serving the Shanghai Textile Industry Bureau (STIB). Non-fasting blood samples were collected for the analysis of several nutrients, including carotenoids and vitamin C. Attempts were made to schedule the diet interview and blood sample collection on or before the date of the scheduled breast biopsy for women with benign or malignant breast disease. Women were excluded from the present analysis if their blood sample collection was completed and their FFQ was

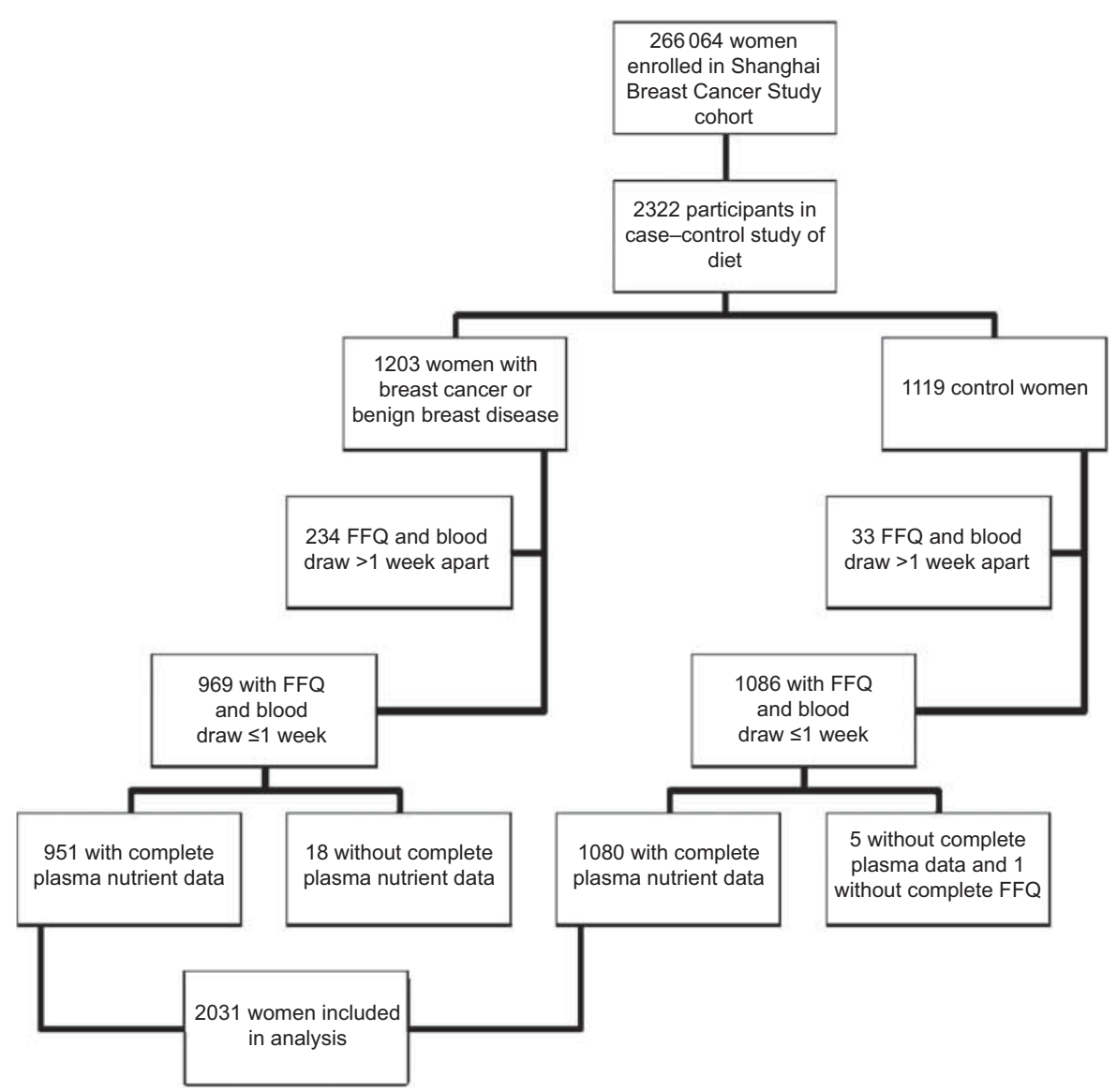

Fig. 1 Female Shanghai textile workers enrolled in a randomized trial of breast self-examination who participated in a nested dietary study 
administered $>1$ week apart or if plasma vitamin $\mathrm{C}$ or any of the plasma carotenoids were missing. The Institutional Review Boards at the Fred Hutchinson Cancer Research Center and STIB approved the study, and informed consent from all participants was obtained before their participation.

\section{FFQ and classification of food groups}

The FFQ consisted of 107 food items and was administered during an in-person interview. Women were asked 'During most of your adult life how often did you usually eat?' for each of the FFQ food items. Women responded by citing the number of times per day, week, month or year, or they indicated that they had never consumed the item. Foods were classified using a three-grouping system: the traditional group, the botanical group and the highnutrient group (containing foods high in the nutrient). The botanical groups were included because certain phytochemicals may aggregate within the botanical groups distinct from the high-nutrient groups. The traditional groups were mutually exclusive and consisted of fruit, vegetables, red meat, poultry, seafood, eggs, milk and milk products, soya foods, legumes excluding soya and grains excluding corn. Fruits included apples, pears, oranges/tangerines, lychee, bananas, peaches, persimmon, pineapple, grapes, apricots and watermelon. Vegetables included salted mustard greens, other salted vegetables, bok choy, spinach, cabbage, Chinese cabbage, watercress, broccoli, Chinese broccoli, green asparagus, cauliflower, celery, eggplant, wild rice stem, winter squash, lettuce, yellow sweet potatoes or yam, other potatoes, wax gourd, gherkins, carrots, pumpkin, mushrooms, red or green pepper, tomatoes, bamboo shoots, radish/turnip, lotus rhizomes, taro root, corn, onions and chives, garlic stalk and seaweed. Table 1 provides examples of foods included in each botanical group. Foods included in the botanical and high-nutrient groups have been published in detail elsewhere ${ }^{(10)}$. The high-nutrient groups were not mutually exclusive with respect to included foods, and included groups for high $\alpha$-carotene (carrots, pumpkin, string beans, winter squash), high $\beta$-carotene (apricots, bok choy, broccoli, carrots, Chinese broccoli, Chinese cabbage, persimmon, pumpkin, salted mustard greens, spinach, string beans, watercress, winter squash, yellow sweet potato or yam), high $\beta$-cryptoxanthin (corn, oranges/tangerines, persimmon, watermelon), high lutein +zeaxanthin (broccoli, Chinese broccoli, corn, hyacinth beans, salted mustard greens, seaweed, spinach, watercress), high lycopene (persimmon, tomatoes, watermelon) and high total carotenoids (apricots, bok choy, broccoli, carrots, Chinese broccoli, Chinese cabbage, persimmon, pumpkin, salted mustard greens, red or green peppers, seaweed, spinach, tomato, watercress, watermelon, yellow sweet potato or yam).

Table 1 Summary statistics for intakes of fruit and vegetables in 2031 Chinese women in Shanghai (1995-2001)

\begin{tabular}{|c|c|c|c|c|c|c|c|c|}
\hline Dietary intake (servings/week) & Mean & SD & Range & 25th percentile & Median & 75th percentile & Kurtosis & Skewness \\
\hline Fruit* & $6 \cdot 4$ & $3 \cdot 7$ & $0-60$ & $3 \cdot 8$ & $5 \cdot 7$ & $8 \cdot 2$ & $2 \cdot 43$ & $25 \cdot 8$ \\
\hline Vegetablest & $15 \cdot 7$ & $6 \cdot 8$ & $3-56$ & $10 \cdot 8$ & $14 \cdot 8$ & $19 \cdot \overline{5}$ & $1 \cdot 01$ & $4 \cdot 87$ \\
\hline Unsalted vegetables & $14 \cdot 6$ & $6 \cdot 6$ & $2-49$ & $9 \cdot 7$ & $13 \cdot 6$ & $18 \cdot 4$ & $1 \cdot 01$ & $4 \cdot 70$ \\
\hline Salted and cured vegetables & $1 \cdot 4$ & $2 \cdot 2$ & $0-18$ & $0 \cdot 3$ & 0.6 & $2 \cdot 0$ & $2 \cdot 32$ & $9 \cdot 66$ \\
\hline Araceae (e.g. taro root) & $0 \cdot 1$ & 0.4 & $0-7$ & 0.06 & $0 \cdot 1$ & $0 \cdot 3$ & $7 \cdot 27$ & 122 \\
\hline Bromeliaceae (e.g. pineapple) & $0 \cdot 0$ & $0 \cdot 2$ & $0-3$ & 0.04 & 0.06 & 0.08 & $5 \cdot 95$ & $63 \cdot 2$ \\
\hline Chenopodiaeceae (e.g. spinach) & $0 \cdot 3$ & $0 . \overline{6}$ & $0-14$ & $0 \cdot 1$ & $0 \cdot 3$ & $0 \cdot 6$ & $14 \cdot 1$ & 389 \\
\hline Compositae (e.g. lettuce) & $0 \cdot 8$ & $1 \cdot 3$ & $0-8$ & 0.2 & $0 \cdot 4$ & $1 \cdot 1$ & 3.05 & $13 \cdot 7$ \\
\hline $\begin{array}{l}\text { Convolvulaceae/dioscoreaeceae } \\
\text { (e.g. yellow sweet potato) }\end{array}$ & $0 \cdot 0$ & 0.2 & $0-4$ & 0.02 & 0.06 & 0.08 & $8 \cdot 29$ & 122 \\
\hline Cruciferae (e.g. bok choy) & $5 \cdot 0$ & $2 \cdot 8$ & $0-36$ & $3 \cdot 0$ & $4 \cdot 6$ & $6 \cdot 8$ & $1 \cdot 89$ & $14 \cdot 6$ \\
\hline Cucurbitaceae (e.g. squash) & $3 \cdot 7$ & $1 \cdot 6$ & $0-14$ & $2 \cdot 7$ & 3.5 & $4 \cdot 6$ & $1 \cdot 23$ & $7 \cdot 01$ \\
\hline Ebenaceae (e.g. persimmon) & $0 \cdot 1$ & $0 \cdot 3$ & $0-4$ & 0.04 & 0.06 & 0.2 & $4 \cdot 58$ & $34 \cdot 8$ \\
\hline Graminae (e.g. bamboo shoots) & 0.6 & 0.7 & $0-8$ & 0.3 & 0.5 & $0 . \overline{9}$ & $3 \cdot 21$ & $26 \cdot 1$ \\
\hline Laminariaeceae (e.g. seaweed) & $0 \cdot 2$ & $0 \cdot 4$ & $0-4$ & 0.04 & 0.2 & $0 \cdot 3$ & $3 \cdot 76$ & $25 \cdot 3$ \\
\hline Liliaceae (e.g. onions) & $3 \cdot 4$ & 3.5 & $0-30$ & 0.5 & $2 \cdot 1$ & $7 \cdot 0$ & $1 \cdot 28$ & $6 \cdot 10$ \\
\hline Musaceae (e.g. bananas) & $0 \cdot 7$ & $1 \cdot 0$ & $0-7$ & $0 \cdot 2$ & 0.5 & $1 \cdot 2$ & $3 \cdot 24$ & $18 \cdot 0$ \\
\hline Nymphaeaceae (e.g. lotus rhizomes) & $0 \cdot 0$ & 0.2 & $0-2$ & 0.04 & 0.08 & $0 \cdot 1$ & $5 \cdot 05$ & $52 \cdot 2$ \\
\hline Rosaceae (e.g. apples) & $2 \cdot 5$ & $2 \cdot 3$ & $0-51$ & $1 \cdot 0$ & $2 \cdot 0$ & $3 \cdot 6$ & $5 \cdot 37$ & $98 \cdot 2$ \\
\hline Rutaceae (e.g. oranges) & 0.9 & 0.9 & $0-7$ & 0.25 & 0.67 & $1 \cdot 2$ & $2 \cdot 10$ & $11 \cdot 2$ \\
\hline Sapindaceae (e.g. litchis) & $0 \cdot 0$ & $0 \cdot 2$ & $0-2$ & 0.04 & 0.06 & 0.08 & $6 \cdot 73$ & $69 \cdot 0$ \\
\hline Solanaceae (e.g. peppers) & $2 \cdot 7$ & 1.9 & $0-23$ & $1 \cdot 5$ & $2 \cdot 3$ & $3 \cdot 4$ & $2 \cdot 32$ & $14 \cdot 6$ \\
\hline Umbelliferae (e.g. celery) & 0.6 & 0.9 & $0-9$ & $0 \cdot 3$ & 0.4 & $0 \cdot 8$ & $4 \cdot 37$ & 33.9 \\
\hline Vitaceae (e.g. grapes) & $0 \cdot 3$ & 0.6 & $0-4$ & 0.08 & 0.2 & 0.6 & $2 \cdot 43$ & $10 \cdot 1$ \\
\hline High $\beta$-carotene & $6 \cdot 3$ & $3 \cdot 2$ & $0-37$ & $4 \cdot 0$ & $5 \cdot 8$ & $8 \cdot 2$ & $1 \cdot 79$ & $12 \cdot 6$ \\
\hline High lutein + zeathanin & $1 \cdot 3$ & $1 \cdot 1$ & $0-18$ & 0.67 & $1 \cdot 0$ & $1 \cdot 6$ & $4 \cdot 36$ & $46 \cdot 6$ \\
\hline High lycopene & $2 \cdot 9$ & $1 \cdot 3$ & $0-21$ & $2 \cdot 2$ & $2 \cdot 8$ & $3 \cdot 6$ & $2 \cdot 44$ & $26 \cdot 9$ \\
\hline High $\alpha$-carotene & $1 \cdot 7$ & $1 \cdot 1$ & $0-11$ & 0.94 & $1 \cdot 5$ & $2 \cdot 2$ & $2 \cdot 13$ & $12 \cdot 3$ \\
\hline High $\beta$-cryptoxanthin & $2 \cdot 8$ & $1 \cdot 4$ & $0-15$ & $2 \cdot 0$ & $2 \cdot 6$ & $3 \cdot \overline{5}$ & $1 \cdot 75$ & $11 \cdot 9$ \\
\hline High total carotenoid & $8 \cdot 5$ & $3 \cdot 7$ & $0-40$ & $5 \cdot 9$ & $8 \cdot 0$ & $11 \cdot 0$ & $1 \cdot 64$ & $10 \cdot 3$ \\
\hline
\end{tabular}

${ }^{*}$ Fruits included: apples, apricots, bananas, grapes, lychee, oranges or tangerines, peaches, pears, persimmon, pineapple and watermelon.

†Vegetables included: unsalted vegetables (asparagus, bok choy, broccoli, cabbage, Chinese broccoli, Chinese cabbage, spinach and watercress) and salted and cured vegetables (fermented bean curd, salted mustard greens and other salted vegetables). 
The botanical groups were mutually exclusive with respect to included foods and included araliaceae (fresh ginseng, white ginseng powder or extract, red ginseng powder or extract), compositae (sunflower seeds, lettuce), convolvulaceae/dioscoreaceae (yellow sweet potatoes, yam), cruciferae (bok choy broccoli, cabbage, cabbage, cauliflower, Chinese broccoli, Chinese cabbage, radish or turnip, watercress), cucurbitaceae (gherkin, pumpkin, watermelon, wax gourd, winter squash), ebenaceae (persimmon), laminariaceae (seaweed), leguminosae (fresh fava beans, fried bean curd, fried bean curd puff, green or kidney beans, hyacinth beans, mung bean sprouts, mung beans, other dried beans, other soyabean foods, pea or cow peas, peanuts, peanut butter, red pea or green bean groups, soyabean milk, soyabeans, string beans, szuki beans), liliaceae (asparagus, Chinese chives, chives, garlic, garlic stalk, onions, scallions), rosaceae (apples, apricots, peaches, pears), rutaceae (oranges, tangerines), sapindaceae (lychee), solanceae (eggplant, hot pepper, other potato, red or green pepper, tomato), umbelliferae (carrots, celery), vitaceae (grapes) and zingiberaceae (ginger root). Servings per week were calculated for each food group. The average serving size obtained from the Chinese population was used to estimate a serving from the reported frequency for each food item. Each reported frequency was assigned the average serving size for that food item. Average serving sizes were obtained from the 1992 China Health and Nutrition Survey ${ }^{(11)}$.

\section{Plasma collection and nutrient analysis}

Blood samples were collected into foil-covered EDTA $10 \mathrm{ml}$ vacutainers and centrifuged within $45 \mathrm{~min}$ of collection or refrigerated and centrifuged within $2 \mathrm{~h}$ of collection. The samples were centrifuged for $15 \mathrm{~min}$ at $1300 \mathrm{~g}$. Plasma was transferred into $2 \mathrm{ml}$ cryovials and frozen at $-20^{\circ} \mathrm{C}$ for 1 month or at $-70^{\circ} \mathrm{C}$ for longer periods until they were shipped to Seattle. Specimens were shipped to Seattle on dry ice and immediately stored at $-70^{\circ} \mathrm{C}$.

Ascorbic acid concentration measurements have been described in detail elsewhere ${ }^{(12)}$. The intra-assay per cent CV (\%CV) was 6.3 and 1.3 at 0.83 and $1.65 \mathrm{mg} / \mathrm{dl}$, respectively. The inter-assay $\% \mathrm{CV}$ was $8 \cdot 1$ and 5.0 at 0.78 and $1.65 \mathrm{mg} / \mathrm{dl}$, respectively. The extraction of analytes from plasma, the quality control parameters and the HPLC methods for measurements of plasma carotenoids and tocopherols have been published previously ${ }^{(13,14)}$. The HPLC method in the present study included a profile of carotenoids, carotenes, retinols and tocopherols in a single HPLC run and has been described elsewhere ${ }^{(12)}$. The $\% \mathrm{CV}$ for the pooled quality control samples for all analytes was $\leq 10 \%$.

\section{Statistical methods}

Mean and SD were calculated as summary statistics. Because distributions were not normally distributed, data were log transformed before analyses for plasma concentrations of $\beta$-cryptoxanthin, lycopene, $\alpha$-carotene, $\beta$-carotene, retinyl palmitate and vitamin C. Exponentiations of the mean value of the log-transformed nutrients to obtain the geometric mean were performed for presenting the data in the results. Dietary intake was divided into quartiles for analysis. Linear regression was also used to evaluate differences in mean plasma nutrient concentrations across quartiles of intake, adjusted for each woman's age, case-control classification, season of interview and year of interview. The quartile of intake was calculated using the median and 25 th and 75 th percentiles of each food group (Table 1) and was included as a single categorical term in the linear regression models. Season was defined as four 3-month categories (December-February, March-May, June-August and September-November). Year of recruitment was divided into three categories: 1995-1996, 1997-1998 and 19992001. Case-control classification was divided into three groups: controls, women with benign breast disease and women with breast cancer. In order to quantify the differences across seasons and year of interview, dietary intake and plasma nutrients were evaluated in relation to season of interview and year of interview using ANOVA and regression analyses, respectively, adjusted for each woman's age, case-control classification and, for dietary nutrients, total energy $(\mathrm{kJ})$ intake. Analyses using controls only were evaluated, and differences in overall interpretation of the results were unremarkable; therefore, the results of analyses for all participants are presented. A sampling of plots of predicted values compared with standardized residuals was evaluated for heteroscedasticity; plots were consistent with meeting the assumptions of homoscedasicity. Statistical significance was considered at $P<0 \cdot 05$. Analyses were conducted using the STATA statistical software package version $11 \cdot 0$ (StataCorp., College Station, TX, USA).

\section{Results}

Women reported consuming an average of approximately six servings of fruit and sixteen servings of vegetables per week (Table 1). Fresh vegetables contributed to the majority of vegetable intake. The correlation between fruit and vegetable intakes was $r=0 \cdot 39$. Cruciferae, cucurbitaceae, liliaceae, rosaceae and solanaceae were the most frequently consumed fruit and vegetable botanical groups. High $\beta$-carotene, total carotenoid, lycopene and $\beta$-cryptoxanthin foods were the most frequently consumed high-nutrient groups. Weekly servings of high $\beta$-carotene and high total carotenoid foods were highly correlated $(r=0.91)$; therefore, further analyses were conducted with high total carotenoid foods only. Although similar foods were in the high lycopene and high $\beta$ cryptoxanthin groups, weekly servings of these foods were not strongly correlated enough to be considered collinear $(r=0 \cdot 58)$. 
Table 2 Summary statistics for plasma nutrient concentrations in 2031 Chinese women in Shanghai (1995-2001)

\begin{tabular}{|c|c|c|c|c|c|}
\hline Plasma nutrient concentrations & Mean & SD & Range & Kurtosis & Skewness \\
\hline$\beta$-Carotene $(\mu \mathrm{g} / \mathrm{dl})$ & $31 \cdot 8$ & 21.9 & $3 \cdot 00-399$ & $71 \cdot 60$ & $5 \cdot 64$ \\
\hline$\alpha$-Carotene $(\mu \mathrm{g} / \mathrm{dl})$ & $2 \cdot 62$ & $2 \cdot 06$ & $0 \cdot 60-42 \cdot 9$ & 121 & 8.48 \\
\hline Lycopene $(\mu \mathrm{g} / \mathrm{dl})$ & $7 \cdot 40$ & $7 \cdot 20$ & $0 \cdot 80-78 \cdot 1$ & $11 \cdot 7$ & $2 \cdot 42$ \\
\hline$\beta$-Cryptoxanthin $(\mu \mathrm{g} / \mathrm{dl})$ & $14 \cdot 0$ & $14 \cdot 1$ & $1 \cdot 40-160$ & $2 \cdot 95$ & 0.02 \\
\hline Lutein + zeaxanthin $(\mu \mathrm{g} / \mathrm{dl})$ & $37 \cdot 0$ & $16 \cdot 5$ & $7 \cdot 90-184$ & $11 \cdot 1$ & 1.91 \\
\hline Retinol $(\mu \mathrm{g} / \mathrm{dl})$ & $41 \cdot 5$ & $11 \cdot 2$ & $6 \cdot 70-107$ & $5 \cdot 36$ & 0.96 \\
\hline Retinyl palmitate $(\mu \mathrm{g} / \mathrm{dl})$ & $3 \cdot 60$ & $2 \cdot 78$ & $0 \cdot 40-85 \cdot 5$ & 414 & $16 \cdot 5$ \\
\hline$\alpha$-Tocopherol $(\mu \mathrm{g} / \mathrm{ml})$ & $9 \cdot 28$ & $3 \cdot 12$ & $0 \cdot 10-35 \cdot 8$ & $12 \cdot 3$ & $2 \cdot 34$ \\
\hline$\gamma$-Tocopherol $(\mu \mathrm{g} / \mathrm{ml})$ & $2 \cdot 14$ & 0.99 & $0 \cdot 30-9 \cdot 35$ & 8.05 & 1.91 \\
\hline Vitamin $C(\mu \mathrm{g} / \mathrm{ml})$ & $8 \cdot 12$ & $8 \cdot 37$ & $<\mathrm{LOQ}-12 \cdot 1$ & $68 \cdot 8$ & $6 \cdot 61$ \\
\hline
\end{tabular}

LOQ, limit of quantitation.

The distribution of plasma nutrients is presented in Table 2. Wide variation in the plasma concentrations of nutrients was observed among the women.

Fruit intake was significantly and positively associated with plasma concentrations of $\alpha$-tocopherol, $\beta$-cryptoxanthin, retinyl palmitate, lycopene, $\alpha$-carotene, $\beta$-carotene and vitamin C (Table 3). Inverse associations of $\boldsymbol{\gamma}$-tocopherol and lutein + zeaxanthin with fruit intake were observed. Vegetable consumption was significantly and positively associated with $\gamma$-tocopherol and $\beta$-cryptoxanthin. The botanical and high-nutrient groups were associated with plasma nutrients in a manner distinct from association with the fruit and vegetable groups. Almost all groups were positively associated with vitamin $\mathrm{C}$ concentrations. Some groups (e.g. rosaceae) were associated with most nutrient concentrations, whereas other groups (e.g. solanceae) were associated with only a few nutrient concentrations.

Season and year of interview were significantly associated with diet and most plasma nutrients (Table 4). Women reported lower lifetime fruit consumption when interviewed during the summer and autumn months and lower vegetable consumption when interviewed during the autumn months. Fruit and vegetable intakes and mean plasma concentrations of lutein + zeaxanthin, $\gamma$-tocopherol and $\beta$-cryptoxanthin decreased over the course of the study. To evaluate whether decreased fruit and vegetable consumption over time was balanced by increased consumption of other foods, we examined the mean intake of other main food groups in relation to year of interview, adjusted for total enegy (kJ), case-control classification, season of interview and age at interview. Consumption of red meat (mean intake for 1995-1996, 1997-1998 and 1999-2001 was 5·6, 5.3 and 4.8 servings/ week, respectively) and legumes excluding soya $(3 \cdot 5,3 \cdot 2$ and 2.9 servings/week for the respective corresponding time periods) also decreased significantly in relation to year of interview $(P \leq 0 \cdot 001)$. Consumption of poultry $(0 \cdot 8,1 \cdot 0$ and $1 \cdot 0$ servings/week), eggs $(3 \cdot 2,3 \cdot 2$ and $3 \cdot 7$ servings/week), milk and milk products $(3 \cdot 2,3 \cdot 1$ and $4 \cdot 1$ servings/week) and grains excluding corn $(5 \cdot 5,5 \cdot 2$ and 6.9 servings/week) increased significantly $(P \leq 0 \cdot 001)$.
No change in consumption of seafood $(3 \cdot 4,3 \cdot 3$ and $3 \cdot 3$ servings/week) or soya foods $(5 \cdot 6,5 \cdot 2$ and $5 \cdot 4$ servings/ week) was observed $(P>0 \cdot 3)$.

\section{Discussion}

Serum and plasma carotenoids and vitamin C are proposed as biomarkers of fruit and vegetable intakes ${ }^{(15-17)}$. Carotenoids are stored in the liver and blood concentrations provide a marker of long-term exposure. Blood concentration of vitamin $\mathrm{C}$, which is not stored, serves as a short-term marker of exposure ${ }^{(18)}$. In the present study, we observed that fruit intake was associated with most plasma carotenoids and vitamin C. Inverse associations of $\gamma$-tocopherol and lutein + zeaxanthin with fruit intake were observed; it is remarkable that there was no positive association because $\gamma$-tocopherol is found in high amounts in vegetable oils and lutein + zeaxanthin is found in eggs and corn, as well as in green and yellow fruits and vegetables. However, the inverse association may have been observed by chance or may reflect a higher consumption of other foods, such as vegetables, that replaces fruit consumption. Vegetable intake was associated with two of the ten plasma nutrients evaluated, $\beta$-cryptoxanthin and $\gamma$-tocopherol. These observations suggest that the fruit group provides a broad classification of exposure to carotenoids and that the vegetable group provides an index of exposure for select nutrients.

We observed that the high total carotenoid group was positively associated with plasma concentrations of $\alpha$-carotene, $\beta$-cryptoxanthin, lutein + zeathanin, $\gamma$ tocopherol and vitamin $C$. This pattern was distinct from the high lycopene and high $\beta$-cryptoxanthin food groups. Among other plasma nutrients, the high lycopene group was positively associated with plasma lycopene concentrations and the high $\beta$-cryptoxanthin group was positively associated with plasma $\beta$-cryptoxanthin concentrations. These observations suggest that the high total carotenoid group provides a valid assessment of several plasma carotenoids and that the specific carotenoid food groups adequately reflect their specific plasma nutrients. 


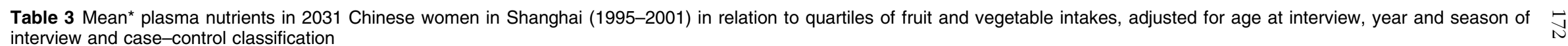

\begin{tabular}{|c|c|c|c|c|c|c|c|c|c|c|}
\hline Food groups (servings/week) & $\begin{array}{c}\beta \text {-Carotene } \\
(\mu \mathrm{g} / \mathrm{dl})\end{array}$ & $\begin{array}{c}\alpha \text {-Carotene } \\
(\mu \mathrm{g} / \mathrm{dl})\end{array}$ & $\begin{array}{l}\text { Lycopene } \\
(\mu \mathrm{g} / \mathrm{dl})\end{array}$ & $\begin{array}{l}\beta \text {-Cryptoxanthin } \\
(\mu \mathrm{g} / \mathrm{dl})\end{array}$ & $\begin{array}{c}\text { Lutein + zeaxanthin } \\
(\mu \mathrm{g} / \mathrm{ml})\end{array}$ & $\begin{array}{l}\text { Retinol } \\
(\mu \mathrm{g} / \mathrm{dl})\end{array}$ & $\begin{array}{l}\text { Retinyl palmitate } \\
(\mu \mathrm{g} / \mathrm{dl})\end{array}$ & $\begin{array}{c}\alpha \text {-Tocopherol } \\
(\mu \mathrm{g} / \mathrm{ml})\end{array}$ & $\begin{array}{c}\gamma \text {-Tocopherol } \\
(\mu \mathrm{g} / \mathrm{ml})\end{array}$ & $\begin{array}{c}\text { Vitamin C } \\
(\mu \mathrm{g} / \mathrm{ml})\end{array}$ \\
\hline \multicolumn{11}{|l|}{ Fruit } \\
\hline Q1 & $25 \cdot 8$ & $2 \cdot 12$ & $4 \cdot 88$ & 8.34 & $37 \cdot 9$ & $40 \cdot 9$ & 3.20 & $9 \cdot 04$ & $2 \cdot 20$ & $7 \cdot 65$ \\
\hline Q2 & $26 \cdot 7$ & $2 \cdot 23$ & $5 \cdot 13$ & $9 \cdot 33$ & $37 \cdot 3$ & $41 \cdot 3$ & 3.25 & $9 \cdot 20$ & $2 \cdot 16$ & 8.03 \\
\hline Q3 & $27 \cdot 7$ & $2 \cdot 35$ & $5 \cdot 40$ & $10 \cdot 4$ & $36 \cdot 7$ & $41 \cdot 7$ & $3 \cdot 31$ & $9 \cdot 36$ & $2 \cdot 12$ & $8 \cdot 40$ \\
\hline Q4 & $28 \cdot 7$ & $2 \cdot 47$ & $5 \cdot 68$ & $11 \cdot 7$ & $36 \cdot 0$ & $42 \cdot 1$ & $3 \cdot 36$ & $9 \cdot 53$ & $2 \cdot 08$ & $8 \cdot 81$ \\
\hline$P$ for trend & 0.002 & $<0.001$ & $<0.001$ & $<0.001$ & 0.049 & 0.084 & 0.034 & 0.009 & 0.037 & $<0.001$ \\
\hline \multicolumn{11}{|l|}{ Vegetables } \\
\hline Q1 & $27 \cdot 1$ & $2 \cdot 26$ & $5 \cdot 20$ & $9 \cdot 44$ & $36 \cdot 8$ & $41 \cdot 1$ & $3 \cdot 31$ & $9 \cdot 20$ & $2 \cdot 08$ & $7 \cdot 97$ \\
\hline Q2 & $27 \cdot 2$ & $2 \cdot 28$ & $5 \cdot 24$ & $9 \cdot 72$ & $36 \cdot 9$ & $41 \cdot 4$ & 3.29 & $9 \cdot 26$ & $2 \cdot 12$ & $8 \cdot 13$ \\
\hline Q3 & $27 \cdot 3$ & $2 \cdot 30$ & $5 \cdot 29$ & $10 \cdot 0$ & $37 \cdot 0$ & $41 \cdot 6$ & 3.27 & $9 \cdot 31$ & $2 \cdot 16$ & $8 \cdot 30$ \\
\hline Q4 & $27 \cdot 3$ & $2 \cdot 33$ & $5 \cdot 33$ & $10 \cdot 3$ & $37 \cdot 1$ & $41 \cdot 9$ & $3 \cdot 24$ & $9 \cdot 37$ & $2 \cdot 20$ & $8 \cdot 47$ \\
\hline$P$ for trend & 0.790 & 0.255 & 0.520 & 0.046 & 0.724 & 0.216 & 0.371 & $0 \cdot 360$ & 0.039 & 0.091 \\
\hline \multicolumn{11}{|l|}{ Cruciferae } \\
\hline Q1 & $25 \cdot 8$ & $2 \cdot 26$ & $5 \cdot 40$ & $9 \cdot 51$ & $35 \cdot 5$ & $41 \cdot 6$ & $3 \cdot 22$ & $9 \cdot 19$ & $2 \cdot 06$ & $7 \cdot 58$ \\
\hline Q2 & $26 \cdot 7$ & $2 \cdot 28$ & $5 \cdot 31$ & $9 \cdot 74$ & $36 \cdot 5$ & 41.5 & 3.26 & $9 \cdot 25$ & $2 \cdot 12$ & $7 \cdot 99$ \\
\hline Q3 & $27 \cdot 7$ & $2 \cdot 30$ & $5 \cdot 22$ & $9 \cdot 98$ & 37.5 & 41.5 & 3.29 & $9 \cdot 31$ & $2 \cdot 17$ & $8 \cdot 44$ \\
\hline Q4 & $28 \cdot 7$ & $2 \cdot 33$ & $5 \cdot 12$ & $10 \cdot 2$ & $38 \cdot 4$ & 41.5 & 3.33 & $9 \cdot 38$ & $2 \cdot 21$ & 8.91 \\
\hline$P$ for trend & 0.001 & 0.260 & 0.178 & 0.098 & 0.003 & 0.903 & 0.156 & $0 \cdot 312$ & 0.012 & $<0.001$ \\
\hline \multicolumn{11}{|l|}{ Cucurbitaceae } \\
\hline Q1 & $25 \cdot 9$ & $2 \cdot 22$ & $5 \cdot 10$ & $9 \cdot 23$ & 36.9 & $41 \cdot 1$ & $3 \cdot 26$ & $9 \cdot 13$ & $2 \cdot 16$ & $7 \cdot 57$ \\
\hline Q2 & $26 \cdot 8$ & $2 \cdot 27$ & $5 \cdot 21$ & $9 \cdot 65$ & $37 \cdot 0$ & $41 \cdot 4$ & 3.27 & $9 \cdot 23$ & $2 \cdot 15$ & $7 \cdot 99$ \\
\hline Q3 & $27 \cdot 7$ & $2 \cdot 32$ & $5 \cdot 32$ & $10 \cdot 1$ & $37 \cdot 0$ & $41 \cdot 7$ & 3.28 & $9 \cdot 34$ & $2 \cdot 14$ & 8.44 \\
\hline Q4 & $28 \cdot 6$ & $2 \cdot 36$ & $5 \cdot 43$ & $10 \cdot 5$ & $37 \cdot 0$ & $42 \cdot 0$ & $3 \cdot 30$ & $9 \cdot 44$ & $2 \cdot 13$ & 8.92 \\
\hline$P$ for trend & 0.003 & 0.036 & $0 \cdot 111$ & 0.003 & 0.965 & $0 \cdot 165$ & 0.616 & 0.093 & 0.595 & $<0.001$ \\
\hline \multicolumn{11}{|l|}{ Liliaceae } \\
\hline Q1 & $28 \cdot 1$ & $2 \cdot 32$ & $5 \cdot 19$ & $10 \cdot 3$ & $38 \cdot 3$ & $40 \cdot 8$ & 3.32 & $9 \cdot 29$ & $2 \cdot 06$ & $8 \cdot 50$ \\
\hline Q2 & $27 \cdot 5$ & $2 \cdot 30$ & $5 \cdot 24$ & $10 \cdot 0$ & $37 \cdot 4$ & $41 \cdot 3$ & 3.29 & $9 \cdot 29$ & $2 \cdot 11$ & $8 \cdot 31$ \\
\hline Q3 & $26 \cdot 9$ & $2 \cdot 28$ & $5 \cdot 29$ & $9 \cdot 72$ & $36 \cdot 5$ & $41 \cdot 8$ & 3.26 & $9 \cdot 28$ & $2 \cdot 17$ & $8 \cdot 11$ \\
\hline Q4 & $26 \cdot 4$ & $2 \cdot 27$ & $5 \cdot 34$ & $9 \cdot 45$ & $35 \cdot 6$ & $42 \cdot 2$ & $3 \cdot 23$ & $9 \cdot 27$ & $2 \cdot 23$ & 7.93 \\
\hline$P$ for trend & 0.080 & 0.486 & 0.453 & 0.066 & 0.005 & 0.035 & 0.282 & 0.913 & 0.005 & 0.065 \\
\hline \multicolumn{11}{|l|}{ Rosaceae } \\
\hline Q1 & $25 \cdot 8$ & $2 \cdot 21$ & 5.00 & $8 \cdot 78$ & $37 \cdot 4$ & $41 \cdot 1$ & 3.20 & $9 \cdot 13$ & $2 \cdot 20$ & $7 \cdot 73$ \\
\hline Q2 & $26 \cdot 7$ & $2 \cdot 26$ & $5 \cdot 18$ & $9 \cdot 49$ & $37 \cdot 1$ & $41 \cdot 4$ & 3.25 & $9 \cdot 23$ & $2 \cdot 16$ & 8.05 \\
\hline Q3 & $27 \cdot 7$ & $2 \cdot 32$ & $5 \cdot 35$ & $10 \cdot 3$ & $36 \cdot 8$ & 41.6 & 3.30 & $9 \cdot 34$ & $2 \cdot 12$ & 8.39 \\
\hline Q4 & $28 \cdot 8$ & $2 \cdot 37$ & $5 \cdot 54$ & $11 \cdot 1$ & $36 \cdot 6$ & 41.9 & $3 \cdot 36$ & $9 \cdot 44$ & $2 \cdot 10$ & $8 \cdot 74$ \\
\hline$P$ for trend & 0.001 & 0.013 & 0.008 & $<0.001$ & 0.382 & 0.247 & 0.038 & 0.086 & 0.044 & 0.001 \\
\hline \multicolumn{11}{|l|}{ Solanaceae } \\
\hline Q1 & $27 \cdot 2$ & $2 \cdot 26$ & 5.06 & $9 \cdot 48$ & 36.9 & $41 \cdot 6$ & $3 \cdot 31$ & $9 \cdot 34$ & $2 \cdot 11$ & $7 \cdot 92$ \\
\hline Q2 & $27 \cdot 2$ & $2 \cdot 28$ & $5 \cdot 20$ & $9 \cdot 73$ & $37 \cdot 0$ & 41.6 & 3.29 & $9 \cdot 30$ & $2 \cdot 13$ & $8 \cdot 11$ \\
\hline Q3 & $27 \cdot \overline{2}$ & $2 \cdot 30$ & $5 \cdot 33$ & $10 \cdot 0$ & $37 \cdot 0$ & 41.5 & 3.27 & $9 \cdot 26$ & $2 \cdot 15$ & $8 \cdot 32$ \\
\hline Q4 & $27 \cdot 2$ & $2 \cdot 33$ & $5 \cdot 48$ & $10 \cdot 3$ & $37 \cdot 0$ & $41 \cdot 4$ & $3 \cdot 24$ & $9 \cdot 23$ & $2 \cdot 17$ & $8 \cdot 52$ \\
\hline$P$ for trend & 0.980 & $0 \cdot 280$ & 0.042 & 0.072 & 0.962 & 0.704 & 0.378 & 0.516 & 0.334 & 0.043 \\
\hline \multicolumn{11}{|l|}{$\begin{array}{l}\text { High total carotenoid fruit and } \\
\text { vegetables }\end{array}$} \\
\hline Q1 & $26 \cdot 4$ & $2 \cdot 22$ & $5 \cdot 34$ & $9 \cdot 38$ & $36 \cdot 0$ & $41 \cdot 4$ & $3 \cdot 26$ & $9 \cdot 20$ & $2 \cdot 07$ & $7 \cdot 65$ \\
\hline Q2 & $27 \cdot 0$ & $2 \cdot 27$ & $5 \cdot 29$ & $9 \cdot 70$ & $36 \cdot 6$ & 41.5 & 3.27 & $9 \cdot 26$ & $2 \cdot 12$ & 8.02 \\
\hline Q3 & $27 \cdot 5$ & $2 \cdot 32$ & $5 \cdot 24$ & $10 \cdot 0$ & $37 \cdot 3$ & 41.5 & $3 \cdot 28$ & $9 \cdot 31$ & $2 \cdot 16$ & $8 \cdot 41$ \\
\hline Q4 & $28 \cdot 1$ & $2 \cdot 36$ & $5 \cdot 20$ & $10 \cdot 4$ & $38 \cdot 0$ & $41 \cdot 6$ & $3 \cdot 29$ & $9 \cdot 37$ & $2 \cdot 21$ & $8 \cdot 83$ \\
\hline$P$ for trend & 0.072 & 0.035 & 0.491 & 0.025 & 0.038 & 0.738 & 0.636 & 0.365 & 0.016 & $<0.001$ \\
\hline
\end{tabular}


A strength of using these high-nutrient classifications is that, although they are a finer stratification compared with fruit and vegetables, there is adequate variation in intake. A limitation of using these classifications is that it may be more difficult to provide public health recommendations regarding consumption of the high-nutrient groups compared with public health recommendations for increased consumption of fruit and vegetables in general.

Fruits and vegetables can be classified on the basis of their botanical family groups, such as cruciferae, or on the basis of their highly specific phytochemical content, such as isoflavones in soya or glucosinolates in cruciferous vegetables. Evaluating the associations between these groups and disease risk is useful for generating and evaluating hypotheses regarding risk associated with particular phytochemicals found in high amounts in these botanical families. We observed patterns of association distinct from the other classifications with regard to plasma carotenoids for the five categories of botanical groups evaluated. In general, the patterns of association were consistent with what might be expected. For example, cruciferae was positively associated with $\beta$-carotene, lutein + zeaxanthin, $\gamma$-tocopherol and vitamin $C$, and solanceae, which includes eggplant and peppers, was positively associated with lycopene and vitamin C. This observation suggests that these groups are useful for evaluating particular botanical families of interest. However, rosaceae (apples, pears, peaches and apricots) was associated with most plasma nutrients, suggesting that this botanical family may be serving as a marker of consumption of other foods.

Season of interview was associated with fruit and vegetable intakes and with plasma nutrient concentrations. Consumption of overall and particular fruits and vegetables is usually seasonal, based on availability and pricing, and therefore changes in plasma nutrients likely reflect changes in consumption. For example, plasma lycopene was higher in summer months and lutein + zeaxanthin was lower in autumn months, which may reflect seasonal changes in consumption of high lycopene foods (e.g. persimmon, tomato and watermelon) or high lutein + zeaxanthin foods (e.g. perishable greens). The FFQ queried participants about their usual intake of particular foods during their adult life. Association of season of interview with fruit and vegetable intakes likely reflects a source of error in dietary exposure measurement, in which participants extrapolate current exposure to lifetime exposure. As a result, season of interview is associated with exposure (diet) and could introduce non-differential or differential bias when evaluating an exposure-outcome association, depending on the relationship of season of interview with outcome ${ }^{(19)}$.

Year of interview was also associated with fruit and vegetable intakes and with plasma nutrient concentrations. Plasma $\beta$-cryptoxanthin, $\gamma$-tocopherol and vitamin $C$ were associated with vegetable intake. $\beta$-Cryptoxanthin 
Table 4 Mean* of weekly fruit and vegetable intakes and of plasma nutrients in 2031 Chinese women in Shanghai (1995-2001) in relation to season and year of interview, adjusted for age at interview and case-control classification. Fruit and vegetable intakes were also adjusted for total energy intake

\begin{tabular}{|c|c|c|c|c|c|c|c|c|c|}
\hline & \multicolumn{5}{|c|}{ Season of interviewt } & \multicolumn{4}{|c|}{ Year of interview } \\
\hline & $\begin{array}{l}\text { Winter } \\
(n 601)\end{array}$ & $\begin{array}{l}\text { Spring } \\
(n \text { 600) }\end{array}$ & $\begin{array}{l}\text { Summer } \\
\text { (n 373) }\end{array}$ & $\begin{array}{l}\text { Autumn } \\
\text { (n 457) }\end{array}$ & $P$ value $\ddagger$ & $\begin{array}{l}1995,1996 \\
(n 442)\end{array}$ & $\begin{array}{l}1997,1998 \\
(n 494)\end{array}$ & $\begin{array}{c}1999,2000,2001 \\
(n 1095)\end{array}$ & $P$ for trend§ \\
\hline \multicolumn{10}{|l|}{ Intake (servings/week) } \\
\hline Fruit & $6 \cdot 4$ & $6 \cdot 7$ & $6 \cdot 0$ & $6 \cdot 2$ & $<0.001$ & $7 \cdot 5$ & $7 \cdot 2$ & $5 \cdot 5$ & $<0.001$ \\
\hline Vegetables & 16 & 16 & 16 & 15 & 0.003 & 18 & 17 & 14 & $<0.001$ \\
\hline \multicolumn{10}{|l|}{ Plasma concentrations } \\
\hline$\beta$-Carotene $(\mu \mathrm{g} / \mathrm{dl})$ & $31 \cdot 0$ & $31 \cdot 1$ & $31 \cdot 2$ & $28 \cdot 9$ & $0 \cdot 132$ & $31 \cdot 9$ & $28 \cdot 3$ & $31 \cdot 1$ & 0.562 \\
\hline$\alpha$-Carotene $(\mu \mathrm{g} / \mathrm{dl})$ & $2 \cdot 76$ & $2 \cdot 33$ & $2 \cdot 36$ & 2.99 & $<0.001$ & $2 \cdot 61$ & $2 \cdot 58$ & $2 \cdot 62$ & 0.934 \\
\hline Lycopene $(\mu \mathrm{g} / \mathrm{dl})$ & 8.97 & $13 \cdot 2$ & $26 \cdot 6$ & $13 \cdot 3$ & $<0.001$ & $14 \cdot 4$ & $14 \cdot 6$ & $14 \cdot 1$ & 0.542 \\
\hline$\beta$-Cryptoxanthin $(\mu \mathrm{g} / \mathrm{dl})$ & $19 \cdot 2$ & $13 \cdot 4$ & $6 \cdot 39$ & $11 \cdot 2$ & $<0.001$ & $14 \cdot 3$ & $15 \cdot 6$ & $11 \cdot 8$ & $<0.001$ \\
\hline Lutein + zeaxanthin $(\mu \mathrm{g} / \mathrm{dl})$ & $38 \cdot 9$ & $40 \cdot 8$ & $35 \cdot 5$ & $30 \cdot 6$ & $<0.001$ & $41 \cdot 5$ & $37 \cdot 0$ & $35 \cdot 2$ & $<0.001$ \\
\hline Retinol $(\mu \mathrm{g} / \mathrm{dl})$ & $40 \cdot 7$ & $41 \cdot 4$ & $41 \cdot 6$ & $42 \cdot 6$ & 0.044 & $40 \cdot 3$ & $42 \cdot 1$ & $41 \cdot 7$ & 0.042 \\
\hline Retinyl palmitate $(\mu \mathrm{g} / \mathrm{dl})$ & 3.55 & 3.53 & $3 \cdot 75$ & $3 \cdot 50$ & 0.433 & $3 \cdot 70$ & $3 \cdot 53$ & $3 \cdot 53$ & 0.306 \\
\hline$\alpha$-Tocopherol $(\mu \mathrm{g} / \mathrm{ml})$ & $9 \cdot 35$ & $9 \cdot 17$ & $9 \cdot 05$ & $9 \cdot 54$ & $0 \cdot 081$ & $9 \cdot 18$ & $9 \cdot 04$ & $9 \cdot 44$ & $0 \cdot 162$ \\
\hline$\gamma$-Tocopherol $(\mu \mathrm{g} / \mathrm{ml})$ & $2 \cdot 14$ & $2 \cdot 19$ & $2 \cdot 17$ & $2 \cdot 06$ & $0 \cdot 188$ & $2 \cdot 22$ & $2 \cdot 18$ & $2 \cdot 09$ & 0.037 \\
\hline Vitamin $C(\mu \mathrm{g} / \mathrm{ml})$ & $7 \cdot 92$ & $7 \cdot 41$ & $6 \cdot 68$ & $6 \cdot 19$ & $<0.001$ & $7 \cdot 56$ & $5 \cdot 90$ & $7 \cdot 56$ & 0.902 \\
\hline
\end{tabular}

*Geometric means for $\beta$-cryptoxanthin, lycopene, $\alpha$-carotene, $\beta$-carotene, retinyl palmitate and vitamin $\mathrm{C}$.

+Winter: December, January and February; Spring: March, April and May; Summer: June, July and August; Autumn: September, October and November. $\ddagger P$ value for difference between categories calculated from ANOVA.

$\S P$ value for linear trend across categories calculated from linear regression.

and $\boldsymbol{\gamma}$-tocopherol, which are stored in the liver and reflect a longer period of exposure, were also inversely associated with year of interview, whereas vitamin C, which reflects a shorter exposure period, was not associated. Red meat and legume consumption also decreased over the course of the study, whereas consumption of poultry, milk and milk products and grain increased. Overall, these observations suggest that the reported decreased fruit and vegetable intakes may represent a real trend of changing consumption patterns. There are many possible reasons for a decrease in fruit and vegetable consumption with time, including increased urbanization, although this has not been predicted to have a remarkable influence on China's vegetable and fruit consumption ${ }^{(20)}$, and changing availability and cost of fruits and vegetables in response to shifts in import and export practices during $1999-2001^{(21)}$. However, it is also possible that the lower fruit and vegetable consumption in later years was observed by chance.

The present study has several potential limitations. One limitation is that the average serving size for the population was used to calculate dietary intake for all participants. Willett summarized results from several studies that indicated that individuals were relatively inaccurate in recalling portion sizes and that the majority of intake variability was from frequency of consumption rather than from serving size ${ }^{(19)}$. Thus, not collecting serving size information likely reduced the intake values but did not markedly alter the overall ranking of individuals by intake. This could be expected to be a minor source of bias across quartiles of intake. However, if a reduction did occur in the variability in dietary intake, this would represent a source of non-differential bias and would have reduced the ability to detect an association between dietary intake and plasma nutrient concentrations. In this circumstance, our results would be conservative. Because a single plasma sample, rather than multiple samples, was collected over time and the single plasma sample was compared with usual adult intake, we expect a decreased ability to detect an association. Overall, these sources of potential non-differential bias in our study suggest that the observed associations between plasma nutrients and dietary fruit and vegetable intakes may be conservative.

Our primary objective was to evaluate the validity of fruit and vegetable intakes obtained from an FFQ by evaluating various classification schemes in relation to plasma carotenoid and vitamin $\mathrm{C}$ concentrations. From this evaluation, we observed several outcomes relevant to the study design and analysis. First, various classifications of fruit and vegetable intakes were associated with plasma carotenoids and vitamin $\mathrm{C}$, suggesting that intakes estimated from the FFQ provide a valid assessment of exposure. Second, the fruit and vegetable, high-nutrient and botanical groups were distinctly associated with plasma nutrients. Third, season of interview should be considered as a potential confounder, or cases and controls should be matched to season of interview. We also observed a significant decrease in fruit and vegetable consumption over time in this population of Chinese women and, given the positive associations of fruit and vegetable intakes with health, this should be evaluated in additional studies.

\section{Acknowledgements}

The present study was supported by the US National Institutes of Health (R01CA75332 and T32CA009168). The authors have no conflict of interest to declare. 
C.L.F. contributed to statistical analyses, manuscript preparation and manuscript review; J.W.L. contributed to study design, laboratory analyses, manuscript preparation and manuscript review; J.S. contributed to study design, data collection, dietary analyses and manuscript review; D.L.G. was the primary physician contact in Shanghai and also contributed to study design, implementation of study procedures, supervision of data acquisition and manuscript review; W.L. contributed to statistical analyses and manuscript review; R.M.R. oversaw data management and statistical analyses and actively participated in manuscript review; C.C. and I.B.K. were involved in laboratory analyses and manuscript review; D.B.T. was the principal investigator for the breast self-examination trial and for other related protocols that funded the current study and was involved in study design and manuscript review.

\section{References}

1. Bazzano LA, Serdula MK \& Liu S (2003) Dietary intake of fruits and vegetables and risk of cardiovascular disease. Curr Atheroscler Rep 5, 492-499.

2. Gonzalez CA (2006) Nutrition and cancer: the current epidemiological evidence. BrJ Nutr 96, Suppl. 1, S42-S45.

3. Key TJ, Schatzkin A, Willett WC et al. (2004) Diet, nutrition and the prevention of cancer. Public Health Nutr 7, 187-200.

4. van't Veer P, Jansen MC, Klerk M et al. (2000) Fruits and vegetables in the prevention of cancer and cardiovascular disease. Public Health Nutr 3, 103-107.

5. US Department of Health and Human Services \& US Department of Agriculture (2005) Dietary Guidelines for Americans, 6th ed. Washington, DC: US Government Printing Office.

6. Pomerleau J, Lock K, McKee M \& Altmann DR (2004) The challenge of measuring global fruit and vegetable intake. J Nutr 134, 1175-1180

7. Li W, Ray RM, Lampe JW et al. (2005) Dietary and other risk factors in women having fibrocystic breast conditions with and without concurrent breast cancer: a nested case-control study in Shanghai, China. Int J Cancer 115, 981-993.

8. Thomas DB, Gao DL, Ray RM et al. (2002) Randomized trial of breast self-examination in Shanghai: final results. $J$ Natl Cancer Inst 94, 1445-1457.
9. Li W, Ray RM, Lampe JW et al. (2005) Dietary and other risk factors in women having fibrocystic breast conditions with and without concurrent breast cancer: a nested casecontrol study in Shanghai, China. Int $J$ Cancer 115, 981-993.

10. Wu C, Ray RM, Lin MG et al. (2004) A case-control study of risk factors for fibrocystic breast conditions: Shanghai Nutrition and Breast Disease Study, China, 1995-2000. Am J Epidemiol 160, 945-960.

11. Carolina Population Center UoNCaCH (1999) The China Health and Nutrition Survey. Chapel Hill, NC: UoNCaCH.

12. Dijkstra SC, Lampe JW, Ray RM et al. (2010) Biomarkers of dietary exposure are associated with lower risk of breast fibroadenomas in Chinese women. J Nutr 140, 1302-1310.

13. Kalman DA, Goodman GE, Omenn GS et al. (1987) Micronutrient assay for cancer prevention clinical trials: serum retinol, retinyl palmitate, alpha-carotene, and betacarotene with the use of high-performance liquid chromatography. J Natl Cancer Inst 79, 975-982.

14. Zhang C, Williams MA, Sanchez SE et al. (2001) Plasma concentrations of carotenoids, retinol, and tocopherols in preeclamptic and normotensive pregnant women. $A m \mathrm{~J}$ Epidemiol 153, 572-580.

15. Brevik A, Andersen LF, Karlsen A et al. (2004) Six carotenoids in plasma used to assess recommended intake of fruits and vegetables in a controlled feeding study. Eur J Clin Nutr 58, 1166-1173.

16. Pollard J, Wild CP, White KL et al. (2003) Comparison of plasma biomarkers with dietary assessment methods for fruit and vegetable intake. Eur J Clin Nutr 57, 988-998.

17. van Kappel AL, Steghens JP, Zeleniuch-Jacquotte A et al. (2001) Serum carotenoids as biomarkers of fruit and vegetable consumption in the New York Women's Health Study. Public Health Nutr 4, 829-835.

18. Shils M, Olson J, Shike M et al. (editors) (1999) Modern Nutrition in Health and Disease, 9th ed. Philadelphia. PA: Williams \& Wilkins.

19. Armstrong B \& White ERS (1994) Principles in Exposure Measurement in Epidemiology. Oxford: Oxford University Press.

20. Hsu HH, Chern W-S \& Gale F (2002) How will rising income affect the structure of food demand? China's Food and Agriculture: Issues for the 21st Century. Washington, DC: USDA/ERS

21. Shields D \& Huang SW (2004) China's fruit and vegetable trade. Global Trade Patterns in Fruits and Vegetables, pp. 52-63. Washington, DC: USDA/ERS. 